\title{
Litigation against psychiatrists
}

John J. Bradley

In the UK, litigation alleging negligent treatment by psychiatrists as individuals has been mitigated by the fact that from 1990 the NHS took over indemnity for claims against hospital doctors. Consequently the work involving claims for compensation against individual doctors has been considerably reduced for the medical defence organisations. Nevertheless psychiatrists make frequent use of medico-legal advisory services offered by those organisations with possibly even greater frequency than any other specialist group. It should be noted that overall there has been an increase in suspensions and disciplinary inquiries over the past few years and psychiatrists are involved as often as those practising in other specialities, needing legal advice, representation and support over what can be a protracted traumatic experience.

Prior to the introduction of NHS indemnity in 1990, an analysis of 50 consecutive claims against psychiatrists dealt with by the Medical Protection Society showed that $36 \%$ of all claims arose out of suicide and $14 \%$ out of attempted suicide. Thirty-two per cent of claims arose from alleged negligent use of drugs, while only $6 \%$ involved allegations of failure to diagnose nonpsychiatric disorders. A further $6 \%$ related to failure to exercise control over psychotic or learning disabled patients.

Although psychiatrists are at relatively low risk when compared with obstetricians, orthopaedic and cosmetic surgeons, claims and settlements can be high in some cases, such as when a patient has attempted suicide and become paraplegic after falling from a window. In practice very few cases reach trial in court on issues of liability, although some will do so on the amount of damages claimed. Most cases do not reach trial and a high proportion are settled out of court. In a few, denial of liability is accepted by the plaintiff and the case dropped.

In recent years there have only been a few claims arising out of suicide or attempted suicide that have gone to court on liability in the UK, and in those cases judgment was generally given in favour of the defendants. There must have been many cases where the plaintiff was compensated in an out-of-court settlement or after a trial on quantum. The common errors that make such cases indefensible are failure to elicit or appreciate the seriousness of suicidal ideas and initiate appropriate observation, and failure of communication between members of the therapeutic team.

Allegations of negligent use of drugs cover the whole range of prescribing but the commonest single drug implicated in negligence claims has been lithium carbonate. The majority of such claims have been indefensible because of failure to appreciate the dangers of dehydration and the concurrent use of diuretics; failure to monitor thyroid and renal function; and poor communication between laboratory and medical staff over serum lithium results.

There have been allegations of negligence involving doses of neuroleptics outside the BNF range but there appear to have been few claims relating to the side-effects of neuroleptics such as tardive dyskinesia or neuroleptic malignant syndrome. A recent paper (Brabbins et al, 1996) concludes that as the Code of Practice requires that sufficient information be given for the patient to understand the nature, purpose and likely effects of treatment, it is proposed that clinicians should employ a pro forma to record attempts to obtain valid consent. We have to acknowledge the difficulty in finding a balance between providing sufficient information to enable a patient to give real consent and providing so much information that the patient is needlessly frightened and discouraged from taking medication.

Despite the apparent potential for negligence litigation, neither the 1959 nor the 1983 Mental Health Acts for England and Wales seem to have generated many claims. This may be accounted for by the close monitoring of the implementation of the Act by hospital managers and the Mental Health Act Commission. Additionally Section 139 of the Act allows for no civil or criminal proceedings unless a doctor can be shown to have acted in bad faith or without reasonable care. No civil proceedings can be brought without leave of the High Court and no criminal proceedings without the consent of the Director of Public Prosecutions. However, in some of the suicide and attempted suicide cases and also in cases of inadequate control of patients, negligence has been alleged against psychiatrists for failure to initiate a compulsory order and provide adequate security.

Psychiatrists may be the victims of allegations of sexual assault which may lead to criminal 
proceedings and disciplinary hearings by the General Medical Councll (GMC). GPs tend to be more commonly implicated than psychiatrists in this respect but we run a close second. Such allegations are deeply distressing and one of the roles of the Society's medico-legal advisers is to provide ongoing support and arrange representation in court or before the GMC.

Recently there have been some claims for compensation for psychological damage allegedly suffered by patients as a result of inappropriate sexual relationships with their psychiatrists, even though initially it may have appeared that the relationships were with the patients' consent. It is generally agreed that relationships of this kind with current or expatients are both unethical and antitherapeutic and any claims may well have to be settled by the doctor without the help of a medical defence organisation.

\section{References}

Brabbins, C., Butler, J. \& Bentall, R. (1996) Consent to neuroleptic medication or schizophrenia: clinical ethical and legal issues. British Joumal of Psychiatry. 168, 540-544.

J. J. Bradley, Chairman of Council, Medical Protection Society (1988-96)

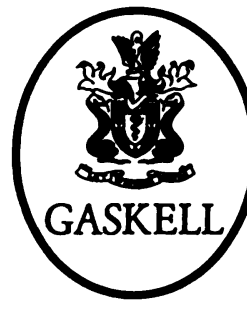

\section{Seminars in Practical Forensic Psychiatry}

Edited by Derek Chiswick \& Rosemary Cope

Seminars in Practical Forensic Psychiatry is a concise account of the specialty from a strongty practical perspective. It systematically describe the relationship between psychiatric disorders and offending, with detailed discussion of the criminal justice system, court proceedings, mental health legislation, dangerousness, prison psychiatry, and civil issues. There are boxes summarising key points, illustrative case examples, and sample court reports. It is up-to-date, with references to the Reed Report, the Clunis Inquiry, supervision registers and recent legislation. Career guidance and a chapter on ethical issues are included. This book will be invaluable for general psychiatrists and for trainees in forensic psychiatry, as well as those other health and social work professionals having contact with mentally disordered offenders, and those who are part of the criminal justice system. Price EI 7.50, 359pp., 1995, ISBN 0902241788

Available from good bookshops and from the Publications Department, Royal College of Psychiatrists, 17 Belgrave Square, London SWIX 8PG (Tel. 0171 -235 235I, extension 146) 